\title{
Regarding "Differences in Hemodynamics and Rupture Rate of Aneurysms at the Bifurcation of the Basilar and Internal Carotid Arteries"
}

W ith great interest and appreciation, we have read the article by Doddasomayajula et $\mathrm{al}^{1}$ entitled "Differences in Hemodynamics and Rupture Rate of Aneurysms at the Bifurcation of the Basilar and Internal Carotid Arteries." They analyzed the differences in hemodynamics at the bifurcation of the basilar and internal carotid arteries to explain why posterior circulation aneurysms have a higher rupture risk than those in the anterior circulation, and they found that higher-flow conditions in basilar tip aneurysms could explain their high rupture risk compared with internal carotid bifurcation aneurysms.

In their article, the typical inlet flow boundary conditions were used for all models. However, the inlet flow boundary conditions of the basilar artery (the posterior circulation) and internal carotid artery (the anterior circulation) could be an obvious difference for the diameter and flow of the inlet artery. Such settings with the same inlet flow boundary conditions of the basilar and internal carotid arteries may disrupt the hemodynamic results markedly in this study, and the conclusions might involve significant bias without considering this factor. To avoid such biases, mirror aneurysms may be an ideal within-patient disease model to provide an internal control for the analysis of possible factors linked to aneurysm rupture. ${ }^{2,3}$ Moreover, patient-specific

http://dx.doi.org/10.3174/ajnr.A5224 inflow boundary conditions may avoid biases in the calculation of hemodynamics when using the computational fluid dynamics techniques. ${ }^{4}$

The authors should be commended for their meticulous instudy design using state-of-the-art methodology. We look forward to future research and discussion.

\section{REFERENCES}

1. Doddasomayajula R, Chung B, Hamzei-Sichani F, et al. Differences in hemodynamics and rupture rate of aneurysms at the bifurcation of the basilar and internal carotid arteries. AJNR Am J Neuroradiol 2017; 38:570-76 CrossRef Medline

2. Tian Z, Zhang Y, Jing L, et al. Rupture risk assessment for mirror aneurysms with different outcomes in the same patient. Front Neurol 2016;7:219 CrossRef Medline

3. Fan J, Wang Y, Liu J, et al. Morphological-hemodynamic characteristics of intracranial bifurcation mirror aneurysms. World Neurosurg 2015;84:114-20.e2 CrossRef Medline

4. Jansen IG, Schneiders JJ, Potters WV, et al. Generalized versus patient-specific inflow boundary conditions in computational fluid dynamics simulations of cerebral aneurysmal hemodynamics. AJNR Am J Neuroradiol 2014;35:1543-48 CrossRef Medline

(D) W. Li (1) Y. Wang

Department of Neurosurgery The First Affiliated Hospital of Nanchang University Nanchang University Nanchang, China 